ALPHA N² 28 Julio 2009 (183-196)

ISSN 0716-4254

http://alpha.ulagos.cl

\title{
DIVAS DE LOS CINCUENTA: MARÍA FÉLIX ${ }^{1}$
}

Ana Pizarro*

No nos referiremos, aquí, a la literatura ilustrada sino a la literatura de masas, es decir, me situaré en un sistema literario diferente del erudito o culto y que evidentemente tiene una densidad estética menor. Nos interesa en la medida en que la literatura de masas es un discurso constructor de la cultura de masas que se da alrededor de los años 1950 en América Latina, instituíyendo, como tal, formas de identidad cultural del continente.

Con aguda percepción escribe Octavio Paz: "La gran creación de María Félix es ella misma”. Más tarde, en su artículo sobre la actriz mexicana reafirma: "María Félix nació dos veces: sus padres la engendraron y ella, después, se inventó a sí misma” (2001:151-152).

María Félix pertenece a un grupo de mujeres que entran al dominio público a través del espectáculo, en la escena del primer momento del cine latinoamericano. Mujeres como ellas se vinculan también al cine norteamericano y europeo en expansión y su vigencia se extiende por lo menos un par de décadas. A estas mujeres, tres entre las más destacadas, les corresponde marcar una imagen de la cultura latinoamericana que se perfila entre los años treinta y cincuenta, proyectándose más allá en la sensibilidad de diversos sectores a lo largo del siglo XX. Se trata de la mexicana María Félix, de la brasileña Carmen Miranda y de la argentina Libertad Lamarque. Hemos pensado en ellas porque son la expresión y, al mismo tiempo, perfilan y potencian con su presencia la imagen de la cultura popular latinoamericana que se extenderá a lo largo del siglo. Es el momento de lo que se llamará popularmente en el norte del continente el tiempo del feeling, con la sensibilidad de la letra y de la música del bolero, en un período en que surge la cultura de masas que circula a través de la radio, el cine y, luego, la televisión.

Por entonces, la sociedad latinoamericana estaba en un proceso de industrialización que habría comenzado alrededor de los años treinta y estas figuras del santuario laico de la cultura popular latinoamericana, al que se ha

${ }^{1}$ Artículo vinculado al proyecto Fondecyt $N^{\circ} 1070102$ (2007) "Fábulas de identidad: el discurso autobiográfico en María Félix, Carmen Miranda y Libertad Lamarque”, en el que la autora actúa como Investigadora Responsable y cuenta como co-investigadora a Carolina Benavente Morales. 


\section{Ana Pizarro}

referido Carlos Monsiváis (2000) provienen de lugares que están a la vanguardia de estos procesos. No es un azar que sus imágenes alcancen difusión internacional. Se trata de países que llevan la delantera en el impulso de un cine para gran público, pioneros en el desarrollo de esta industria, cuyos productos recorren el continente y que conoce su era "dorada” en el momento cuando las metrópolis se enfrascan en la Segunda Guerra Mundial. El ámbito urbano está, al mismo tiempo, en constitución acelerada debido a los movimientos migratorios desde lo rural y hay un engrosamiento de los sectores populares y los sectores medios de la ciudad. Esta dinámica social, encuadrada en el espacio mayor de la comunicación que proviene del campo internacional y en especial de Hollywood, es la que les propondrá a estas mujeres ofertas de sujeto en el momento cuando estas figuras del panteón popular están construyendo sus identidades. Ligadas, pues, a un proceso nacional e internacional de desarrollo de una segunda etapa en la comunicación de masas del siglo - la primera había estado vinculada a la radioubicada cada una en una situación histórica de carácter específico, María Félix, Carmen Miranda y Libertad Lamarque contribuyen a la conformación de una imagen y de una sensibilidad. Nos preguntamos en este contexto y a través de estas figuras - las más afamadas en el espacio de la cultura de los nuevos sectores urbanos - cómo se configura la cultura popular de masas que América Latina muestra alrededor de los años cincuenta y, en este marco, en qué medida estas mujeres, cuya función pública contribuye a diseñarla y expandirla, se relacionan con ella.

Me parece posible encontrar vías de respuesta a través del examen de la construcción de identidades. Efectivamente, cada una de ellas se realiza en un medio histórico-social diferente, en donde deben negociar sus opciones, la expresión de su deseo. Observaremos esta construcción de sujeto a través del espacio biográfico y la autobiografía, que es un texto privilegiado en donde éstas se configuran. ${ }^{2}$ Sabemos lo que es la autobiografía como texto a través de los varios análisis que existen. En la autobiografía se textualizan conformaciones del imaginario que dan cuenta y son, al mismo tiempo, prolongación del contexto social, histórico, político, cultural en donde están insertas. En esta relación el sujeto se produce y es por eso — que en la configuración de su textualidad - se inscriben las formas de una negociación en donde se encuentran, por una parte, el proyecto, el deseo individual, y, por otra, el ámbito social, que establece las exigencias a través de ofertas de sujeto. Siguiendo a Emmanuel Levinas (1993), Ángel Loureiro apunta a lo social como instancia que antecede a la construcción del sujeto, así como a todo

\footnotetext{
${ }^{2}$ Sobre este tema existe una importante bibliografía, que señalaremos en los casos pertinentes.
} 
conocimiento: "el yo se constituye como respuesta al otro y como responsabilidad hacia ese otro”. Por esto mismo, Loureiro afirma que la autobiografía

No es una restauración del pasado, sino un acto singular de autocreación como respuesta, responsabilidad y promesa (de verdad). Como tal este acto es siempre dialógico, está dirigido al otro, y por lo tanto es también intrínsecamente contestable e incompleto (2001:21).

Es decir, si este género fracasa como empresa cognoscitiva, triunfa como acto performativo, como acto de representación.

El trayecto de vida de María Félix lleva a su nacimiento en Álamos, Sonora, en el extremo norte de México en 1914, en el seno de una familia de clase media acomodada, pero sin exceso de fortuna, que se instaló tempranamente en Guadalajara. María Félix tuvo una relación muy cercana con su hermano Pablo, que murió por suicidio, pero ella siempre pensó que lo habían muerto. Su primer matrimonio fue con un agente viajero y tuvieron un hijo, Enrique, que muere años antes que ella. Cuando se separó, se instaló en Ciudad de México y tuvo varias parejas, entre ellas el músico Agustín Lara, el actor Jorge Negrete y, más adelante, un banquero francés adinerado. Ingresó en 1940 al ámbito del cine, industria floreciente en México que en ese momento estaba viviendo su "época dorada”, época que se extiende desde 1935 al año 1955, siendo su mayor auge entre 1941 y 1945.

En 1943 se habían estrenado setenta películas en México y la industria tenía una velocidad inusitada con el apoyo del gobierno. El mexicano era un cine de personajes y estereotipos: charros, prostitutas, cantantes; y el poder dentro de la industria experimenta grandes tensiones entre dirigentes, como William O. Jenkins, un norteamericano que había logrado una cuota importante de poder, y los sindicatos. En esta situación es importante el estallido de la Segunda Guerra Mundial porque ya no hay distribución de películas europeas y Estados Unidos vuelve propagandística su producción. México tiene ventajas sobre la Argentina, el otro gran productor cinematográfico del momento, porque — alejado del Eje - tiene acceso al material virgen de los Estados Unidos. Así, México desarrolla un cine de referente revolucionario, frente al cine nostálgico de la cultura del porfiriato, con su cuota de frivolidad, champaña, lujo y amores recatados. México estaba en un proceso de urbanización muy fuerte, después de 1910, y el D. F. sufrió menos de hambre, escasez, violencia, tomas de ejércitos revolucionarios, desarreglos económicos y miedo, al decir del historiador Sergio González Rodríguez, que el resto del país. En pocos años más sería la llamada "superconcentración industrial”

Entre 1940 y 1970 quedó atrás el rostro antiguo de la ciudad: de los restos de la arquitectura prehispánica, la colonial, los edificios 
Ana Pizarro

porfirianos y las casas pueblerinas, con barrios de aire sereno y cercanías rurales, surgen los primeros rascacielos y construcciones modernas, cúbicas y multitudinarias (González, 1993:262-263).

Desembarcaron en ese período en la capital más de cuatro millones de personas, llegando en 1960 — por primera vez — a ser mayor la población urbana que la rural. La urbanización significó muchos cambios: organización, movilizaciones de los nuevos sectores. Emergen nuevos espacios públicos. La radio, antes de los sesenta fue fundamental en la vida urbana y con la televisión no dejó de ser importante. Entre 1934 y 1958 muchos escritores trabajaban en guiones, radioteatros y "jingles" (el famoso "Mejor mejora Mejoral" entre otros) para la radio, por ejemplo, Xavier Villaurrutia, Salvador Novo y Alfonso Reyes. Las clases populares y las clases medias se habían ampliado y eran el público a quien estaba dirigida esta comunicación radial.

En los años 50 el éxito de las radionovelas era indudable. Era la "hora de la comedia” y las secretarias, amas de casa, telefonistas, obreras, etc., sintonizaban la estación para escuchar vidas de otros, que si bien no eran ciertas, arrancaban gritos, lágrimas, sollozos, lamentos, risas y demás sentimientos a la menor provocación (Avedoy Guerrero, 2006). Grandes estrellas tenían la presencia necesaria para estar allí: María Félix, entre otras.

María Félix, que debió aprender a actuar en el mismo escenario, comenzó con El peñón de las ánimas en 1942, versión mexicana de Romeo y Julieta. Escribe su director, Miguel Zacarías, quien le ayudó a disciplinar su cuerpo para la actuación: "Tuve que pasarme tres meses sentado en la alfombra de su departamento discutiendo, peleando con ella, haciéndola pronunciar la a, la e; enseñándola a hablar, dicción, mímica, a andar, sentarse, todo eso" (Taibo I, 2002:22). M. Félix hizo 47 películas entre las que quedaron en la memoria se cuentan Doña Bárbara (1943), La monja alférez (1944), Río Escondido (1948) y La Generala (1966).

A través del cine mexicano, María Félix se dio a conocer en América Latina y el mundo, destacándose como la figura que ya se impone en Doña Bárbara, de acuerdo al personaje de Rómulo Gallegos, como mujer con corazón de hombre, como ella misma afirma y con la imagen que culmina en su último film (La Generala, 1966). Hay que decir que, en el caso del cine de esos años, se trataba de un tipo de film llamado de "estrellas"; es decir, los filmes estaban hechos para ellas, por lo cual cumplían un papel diferente del cine industrial de hoy o del cine de autor: cumplía, más bien, el papel que se le asigna actualmente a la televisión. "La leyenda de la Félix hombruna - escribe Paco Ignacio Taibo I- de sus pantalones simbólicos y de su ropaje negro y agresor, va a tomar cuerpo de una forma decidida en este film, que parece intentar darnos las claves necesarias para intentar descifrar el misterio 
mexicano de una estrella” (2002:440). El film Enamorada (1946) la introduciría al mundo parisino y a partir de allí su relación con Francia sería permanente. $^{3}$

La autobiografía de la actriz mexicana —que al decir de Enrique Krauze "se ha robado el siglo" y que lleva por título María Félix: todas mis guerras, publicada originalmente en 1993 (Félix, 2005) — presenta respecto del género interesantes problemas. Se trata de un texto especial en su factura. Es un racconto autobiográfico destinado al gran público, como todos los discursos de la Félix en sus innumerables entrevistas, esta vez alentado y moldeado por Krauze quien originalmente había querido escribir una biografía, pero pronto se percató de la imposibilidad de hacerlo, según anota en el prólogo. ${ }^{4}$

Es importante observar entonces, de partida, que hay varios productores del texto - la sujeto de la escritura y sus "afinadores" - con diferente jerarquía. Serna y Krauze ejercen su papel desde lugares distintos y, de alguna manera, su participación expresa, en parte, la concreción del universo social frente al cual la actriz desarrolla su performance. Krauze, Samper y Augé representan a la sociedad en la negociación que da lugar a la escritura. Como señala Marc Augé: "toda representación del individuo es necesariamente una representación del vínculo social que le es consustancial”, y más adelante "lo social comienza con el individuo" (1998:26-27). Se trata, entonces, de un texto privilegiado para la lectura de la relación del sujeto con el vínculo social, de la construcción individual en la dinámica de su inserción en el espacio social. La existencia del distanciamiento está consignada por el mismo Krauze, al citar una imprecación de María: “¿Para qué insistes en buscar eso que tú llamas la verdad? La vida de una actriz es sueño, y si no es sueño no es nada” (2005:15).

En la aproximación a los textos autobiográficos no se trata, pues, de llevar a cabo un análisis comparativo texto / referente o fabulación / "verdad". El texto autobiográfico es una construcción fabulatoria, la escritura de una representación, un acto de lenguaje. Porque, siguiendo la concepción de Paul

\footnotetext{
${ }^{3}$ Rechazó entrar en Hollywood, pero se vinculó con el cine europeo y especialmente francés, en una relación que duraría hasta su muerte, en 2002 (Samper, 2005), lo que responde a una vocación de las clases altas en América Latina.

4 “La solución no era la biografía sino la autobiografía. No sería difícil armarla. Las grabaciones consignaban ya una literatura oral que con leves afinaciones pasaría limpiamente a la página. Así nació este libro que me contó María Félix y que Enrique Serna, meticulosamente, transcribió y editó. Su contenido, como su título es la verdad de María: la bitácora de todas sus guerras”, Enrique Krauze. “Corazón de hombre”. Prólogo a María Félix. Todas mis guerras. México: Clío, 2005, 15. Citaremos por esta edición.
} 


\section{Ana Pizarro}

De Man (1979), es el discurso el que funda la vida, produciendo una ilusión de referencia. Anota Eva Klein, al respecto: "De repente la autobiografía ya no es la narración de la verdad, sino la simulación, la máscara, la impostura" (2006:44). Recordemos que el escritor argentino-francés Héctor Bianciotti habla respecto de sus textos no de autobiografía sino de "autoficción”. En la problematización del referente, E. Klein articula el pensamiento de los posestructuralistas anotando

El planteamiento de De Man, que supone que la autobiografía funda la vida y no al revés, se relaciona muy bien con el planteamiento de Foucault, quien propone que todo saber se organiza en el orden del discurso. Por otra parte también Foucault con sus "tecnologías del yo" ayuda a entender la fragmentación del sujeto, fragmentación que en el discurso trata de construirse como algo homogéneo, y finalmente, Jacques Lacan, especialmente en Escritos I, señala que la identidad se deriva de la dialéctica entre el sujeto y las ficciones que él o ella proyecta en el espejo o en cualquier otra estructura que devuelva una imagen coherente (2006:45).

Es decir, el interés por la autobiografía se ha ido desplazando desde la idea tradicional que la consigna como representación de vida, hacia la de un acto performativo, una representación de la vida que se crea en el momento de la escritura.

En el caso de María Félix, esta representación -la captación de su discurso oral - está intervenida por un (dos, en realidad) mediador que responde a la representación social y que desde esta perspectiva interviene el discurso original ("leves afinaciones”, "transcribió y editó”). Pero más que interventores, los mediadores son una presencia en la oralidad del texto. Es decir, en este discurso la presencia de las dos voces - la individual y la social— están explícitamente en juego, más allá de la dialéctica social individual de la voz que emite el discurso original en donde la sociedad es una presencia ausente. Este juego queda, tal vez, muy en evidencia en la intencionalidad representativa de coherencia del discurso global, organizado en ítems como "Corazón de hombre”, "El ansia de libertad”, “A la conquista de Europa”, entre otros. De alguna manera es un discurso que María considera entender y manejar, por ello explica a su público: "Estoy hecha de todo el pasado y he aprendido mucho de los hombres que vivieron conmigo, pero en realidad el pasado no me interesa. Me interesa el presente, lo que voy a hacer hoy o mañana” (2005:249). Pareciera una postura formalmente coherente, el mundo ordenado, pero ordenado desde el exterior de ella misma, en donde las contradicciones, si las hay, están racionalizadas. 
Sin embargo, enseguida agrega su interés por el elogio que Octavio Paz escribió sobre ella o por la ópera (2005:250) basada en su vida que estrenará un compositor argentino en París, contradiciendo su opción por el futuro dentro de su misma percepción, pero asumiendo, sin quererlo, la lectura del presente como un tiempo múltiple, en relación permanente y no secuencial con el pasado y el proyecto de futuro. Símbolo de la modernidad, María Félix cree entenderse sin fisuras, como una afirmación, sin dudas, con todos los filamentos orgánicamente conectados, y es así como percibe racionalmente el tiempo como un continuum, separando instancias de pasado, presente y futuro en donde el sujeto se relaciona ordenadamente con cada una de ellas.

Diríamos que es exactamente el caso contrario a una percepción múltiple y conflictiva del yo que está presente en Agua Viva (1973) —otro texto, también autobiográfico- de Clarice Lispector, donde es posible advertir, como lo hace Márgara Russotto (2006:437-458), pulsiones sin dirección, incoherencia de la interioridad. El texto mismo es, allí, persecución infinita del instante en lugar de narración conclusiva de una búsqueda. María Félix experimenta la existencia de un tiempo múltiple, pero su discurso racionaliza el devenir de otro modo. Es por eso que necesitamos perfilar el camino a la verdad autobiográfica como siempre indirecto. Pero no debemos equivocarnos, ésta es una verdad que no está fuera del texto, sino en sus propias pulsiones, en las instancias de su movimiento, en lo imperceptible de sus inflexiones.

¿Cuáles son los rasgos del sujeto que María Félix construye en esta autobiografía? ¿Cuál es la representación de sí misma y a quién o quiénes está dirigida, más allá del narratario a quien entrega su discurso oral y quién participa en esa construcción? Es decir ¿Cuáles son las ofertas que la sociedad le hace y cuáles son las opciones que establece la diva?

El texto comienza con una expresión definitoria: "Aquí estoy, desentilichando el alma” (2005:21). Se trata, aquí, de una afirmación, de una dirección del discurso y de un desafío. Es la Félix tal cual ella ha querido presentarse al público: “Aquí estoy” es la valentía desafiante; “Aquí estoy”; frente a amigos, a desconocidos y a enemigos. El desafío se instala desde la primera frase (¿Estrategia de presentación de Enrique Krauze?). Sea como fuere, aquí está diseñada la actitud fundamental del discurso autobiográfico. La actitud del desafío, que, evidentemente, es una postura valorada popularmente, sobre todo en un país que ha vivido una revolución armada, y que sostiene durante todo el siglo XX un discurso de nación "revolucionaria”, más allá del contenido demagógico, o no, de ello. El título elegido tiene que ver también con esta oferta de sujeto: la actitud guerrera, desafiante en términos bélicos, el valor del heroismo. Además de esto, en la afirmación del léxico nacionalista — “desentilichando”- se apuesta, por una parte, a un 
receptor cercano (el mexicano) pero, también, se trata de una afirmación desafiante de pertenecía nacional frente a un público internacional, puesto que es un discurso para el presente y para el futuro.

La autobiografía tradicional del siglo XIX era, como el retratismo, el momento adecuado para establecer hitos en la memoria histórica pública. En cambio, en el siglo XX, el sujeto se instala en un universo menos elitista, desdibujándose más bien en la masa. Las obras de narradores de la primera mitad del siglo en Europa así lo escenifican: el sujeto de Franz Kafka o Albert Camus, aparecen difuminados y casi sin nombre, que es lo que logrará luego Nathalie Sarraute.

Contrariamente a ese yo monumental diseñado por hombres que en el XIX que escribían su autobiografía, el diario de mujeres tiene, en general, un carácter intimista que empequeñece al sujeto, que lo sitúa en el terreno de lo privado y más aún, de lo íntimo, en forma acorde al lugar social de la mujer. Lo interesante que encontramos en la autobiografía de María Félix es la construcción de un yo monumental a partir no sólo de elementos públicos, sino que en su discurso torna monumental, también, lo privado y aún lo íntimo: describe con detalle sus actividades cotidianas, desde que despierta, su desayuno, su gimnasia, etc. Pero, además, entra en un campo mucho más íntimo. "Llegué al tálamo virgen como un botón y sentí el desfloramiento como una agresión tremenda” (2005:95), señala respecto de su primer matrimonio, mientras afirma, al describir a Agustín Lara, que "como amante era una maravilla” (2005:95). Es decir, estamos en los inicios de la formación de un espacio público masivo, que construyen los medios de comunicación —que hoy llamamos "farándula" - en donde lo personal y privado se instala en lo público rescatando para sí, su interés.

Ahora bien, en el caso de María Félix es una farándula con elementos de lo que hoy entendemos por tal, ligada a las mundanidades y al poder económico: los nombres del rey Farouk, Cristian Dior y otros se dejan ver en el texto de la Félix. Pero, también, con un carácter muy diferente del que tiene la farándula actual: María se perfila en sus escritos autobiográficos como una mujer ligada a los grandes intelectuales de la época, situación de la que se ufana - "En el círculo del talento, donde yo me he movido siempre" (2005:181) - y no pierde ocasión de citar nombres que la legitiman en este ámbito: Leonora Carrington, Frida Kalho, Diego Rivera, entre los que viven en México y a quienes dedica largos párrafos. Pero, también, la intelectuallidad internacional: Jean Cocteau, Colette, Sacha Guitry, Jean Genet, Max Ernst, Salvador Dalí, entre otros. El texto denota en ello una preocupación. María Félix se perfila, a sí misma, como parte de esta cúpula social que llama “aristocracia del intelecto". Hay en esto, desde luego, un resabio del origen, la clase media acomodada de Sonora, emergiendo de entre una masa de 
analfabetismo, universo de excepción que valora el prestigio del mundo intelectual letrado y artístico y que se asume como diferente. María sabe situarse como imagen a lo largo de su vida en el cruce entre este círculo privilegiado y la masa a quien llega la información mediática. Hay aquí, entonces, un perfil de sujeto que le está proponiendo el medio cultural y social de origen y al cual ella accede.

\section{¿CUÁLES SON LOS ELEMENTOS QUE CONSTRUYEN A ESE SUJETO?}

Primeramente, se trata de un yo autocentrado que se reafirma con marcas permanentes en el texto: "Yo enérgica, arrogante, mandona" (198); "El cine actual ya no tiene figuras como la Garbo y como yo" (224); "Sólo tengo un mensaje para las mujeres de mi país y del mundo: ojalá se quieran tanto como yo me quise" (258); "lo que más me gusta en el amor es querer, pues querida lo he sido siempre, a veces demasiado" (30). Estamos frente a diversas expresiones, referidas a diferentes etapas de la vida de quien, desde muy temprano, se ha forjado un destino. Este destino es el del éxito: "Entre mis guerras no menciono el éxito porque no me costó ningún trabajo obtenerlo” (25). Esta focalización de un destino para sí misma está dada a partir de elementos no construidos ni logrados, sino dados de antemano: "Para mí, la belleza es una condición natural (...) porque fue un regalo de la vida” (25). Entonces, su cuerpo es la premisa para diseñar el logro de su deseo; es un espacio. Es muy interesante, entonces, leer el manejo que hace de su arma en esta guerra con la vida en donde el objetivo es el triunfo. Antes es necesario observar la diferencia que ella hace entre "éxito" y "celebridad": el éxito lo tienes tú mismo. La celebridad te la dan los demás, señala desde el comienzo. Es decir el éxito es la relación del sujeto con su deseo. La celebridad tiene que ver con la relación social ¿Cómo articular entonces al sujeto en construcción, en función de su deseo con "los demás", con la sociedad? María Félix lo hace a través de su arma que es el cuerpo. En esa construcción ficcional que es el yo, el cuerpo tendrá entonces un papel decisivo entre el deseo del sujeto y su logro. El cuerpo será diseñado como espacio de intercambio, según se observa en la cita siguiente

Al poco tiempo de llegar a España recibí un homenaje de Agustín, que todavía no se resignaba a mi ausencia (...). Íbamos entrando al cabaret Villa Fontana cuando Ana María González, al verme llegar, comenzó a cantar el chotis Madrid. Yo sabía que Agustín me lo había dedicado, pero al oírlo por primera vez me sacudió una profunda emoción. Por un momento me quedé parada en el pasillo, con el pulso agitado, recordando al flaco. Luego tuve un gesto de energía y comencé a caminar hacia la mesa de pista que nos habían reservado (115. Cursivas mías). 


\section{Ana Pizarro}

El espacio en que se mueve ese cuerpo entrega el medio que sitúa la vida de la Félix: el restaurant, la vida mundana, el espectáculo. Pareciera que ella es sólo espectáculo, tal cual se presenta a sí misma. Como vemos, en la cita, lo que importa aquí es la gestualidad, ese relato que construye sobre las capacidades de su cuerpo. Los gestos son, desde luego, capacidades performáticas para configurar la imagen de fuerza, altanería, decisión, capacidad de superación pública de las emociones. El cuerpo se disciplina. En el texto, su uso es - al mismo tiempo - la utilización de la belleza como arma de sus "batallas". "No es suficiente ser bonita — le enseña la madre de acuerdo a su relato - hay que saber serlo" (38). El cuerpo, como la identidad, es también una construcción; desde la infancia, entonces, los modales, la gestualidad, los tirantes para no encorvarse. Y, luego, la vestimenta, esa otra forma con que se construye identidad.

En un episodio durante la filmación de El peñón de las ánimas relata: "La tercera dificultad fue con mis vestidos. Querían darme ropa corriente, alegando que una mujer del campo, aunque fuera hija de familia no podía llevar sedas ni encajes. Mandaron a hacer unos vestidos de percal y se los tiré al director en la cara" (74). La vestimenta alude a espacios de convivencia social, a formas de representación; es signo de glamour o de sobriedad, de sofisticación o de simpleza. En ese código, María asume más bien los signos de poder: oro, brillantes, esmeraldas, joyas de las grandes casas parisinas, ropa de Dior. Es por esto que el cuerpo se disciplina no sólo con los modales y la espalda espigada sino con todo su aparataje para ejercer el rol necesario: la seducción. "En el cine y en la vida — sostiene - seducir es más importante que agradar” (86). Es a partir de la seducción, sin concesiones, como María Félix tendrá la aceptación del público espectador de sus películas, lector de su discurso o de las revistas de cine y variedades. Su legitimación se da, entonces, vía seducción a partir del disciplinamiento del cuerpo. Pero, hay otros elementos. Entre ellos, la función de su actitud "feminista”, según escribe su biógrafa Samper

Representó, a mediados del siglo pasado a la mujer luchadora, capaz, que se rebelaba en contra del poder de los hombres sobre la figura femenina. Lo hizo desde su vida privada y desde el cine, que era entonces el fenómeno cultural de mayor incidencia en nuestro continente (2005:9).

Es cierto que María Félix representa un tipo de rebelión de mujer dentro del continente. En México había habido una larga lucha en función de las reivindicaciones femeninas que, finalmente, lograron el derecho a voto en $1953 \mathrm{y}$, en especial, en los gobiernos revolucionarios como en el caso de 
Divas de los cincuenta: María Félix

Cárdenas, a quien le interesó esta posición dentro de su discurso igualitarista. Como observa Cano

Conocedor del peso que tenía la imagen del conservadurismo femenino, Cárdenas se ocupó de rebatirla. Señalaba el presidente que las mujeres habían dado muestras reiteradas de actuar a favor de las causas progresistas: "La mujer mexicana viene participando desde hace muchos años en la lucha social del país en proporción muy estimable en calidad y cantidad, y con mucha frecuencia, cuando lo permite nuestro egoísmo, se la ve formando más francas a favor de las ideas más avanzadas" (decía el presidente). En su informe de 1937 Cárdenas también mencionó la contribución femenina a la obra social revolucionaria, en la organización sindical, en el magisterio, en el trabajo y en el hogar (2007:173).

Una situación de última hora no permitió a Cárdenas lograr su cometido, pero lo importante, aquí, es que esta opción es una de las posiciones discursivas en pugna en la sociedad mexicana y es, en ese sentido, como María Félix se incorpora a una de ellas estableciendo, así, un vínculo con parte importante de su sociedad, más allá de constituir una posición en tensión social. Hay, en María Félix, una actitud de desenfado que contrasta con la imagen de sometimiento de la mujer tradicional frente al dominio patriarcal: "A mí ningún hombre me hizo la vida pesada, porque nunca le aposté a uno solo todas mis fichas" (198) escribe. Luego está esa identidad que la hizo famosa de mujer masculinizada. Es importante, aquí, observar dos elementos que parecen anudar la configuración del sujeto al establecimiento del lazo social. Por una parte está la relación al límite incestuosa con su hermano Pablo, un muchacho hermoso de quien ella declara haberse enamorado en la adolescencia. Las imágenes de la memoria delinean un romanticismo novecentista de carreras a caballo con el pelo al viento. Es cierto que en ella son comunes las imágenes kitsch. Pero, al parecer, esta relación lleva a los padres a separarlos y el joven parte a la escuela militar y allí muere. En principio se suicida. Ella afirma que lo han muerto. Esto nunca se aclara. En su autobiografía consignará con su tono clásicamente transgresor: "el perfume del incesto no lo tiene otro amor" (56).

Lo cierto es que este golpe incorpora a María dentro de un proceso de reconstitución emocional y configuración identitaria en donde ella, con reconocido voluntarismo, se apropia, hace suya la imagen del hermano, vistiendo ropas cercanas a las suyas, adoptando posturas varoniles, en una dinámica en que ella es ella y él, al mismo tiempo. Este proceso se articula, además, con su postura de fuerza frente a la sensibilidad masculina. Pareciera que usa a los hombres, o los hermana en términos igualitarios. Curiosamente, 


\section{Ana Pizarro}

y como por encanto, le corresponde asumir, por decisión del mismo Rómulo Gallegos, el papel de Doña Bárbara, un personaje hecho a su medida que no hace sino reafirmar la configuración identitaria en proceso. Si hay, por una parte, esta situación biográfica en donde ella se masculiniza, existe otra situación que tiene que ver con las ofertas de sujeto desde la sociedad. Recordemos que se trata de un país que viene saliendo de una lucha armada, que valora la fuerza, las armas, los signos de masculinidad. Una sociedad machista. Jean Franco escribe respecto de México

El problema de la identidad se presentó básicamente como un problema de identidad masculina, y fueron los autores varones los que discutieron sus defectos y psicoanalizaron a la nación. En las alegorías nacionales, las mujeres se identificaron con el territorio por el que se pasaba al buscar la identidad nacional o, cuando mucho, como en Pedro Páramo, de Juan Rulfo (1955), con el espacio de pérdida, en lo que queda fuera de los relatos masculinos de rivalidad y venganza (1993:172).

María Félix se masculiniza también —-seguramente para enfrentar el poder patriarcal - en el contexto de una sociedad que le ofrece una opción que normalmente no ofrece a las mujeres, pero que ella asume dada su configuración identitaria, que le ha entregado una imagen de mujer castigadora, insensible, fuerte, dura y, al mismo tiempo - y cuando quiereseductora con los subterfugios que ha adquirido en el uso de su cuerpo. Es decir, María Félix responde a una opción del imaginario mexicano de esas décadas, del mismo modo como responde conscientemente a su pertenencia a esa sociedad afirmándose en su discurso: ser sexy es tener un "estilacho" (31).

Al construirse como lo ha hecho, pareciera coherente la negación de María Félix a la maternidad: "El amor de madre siempre me ha parecido la cosa más cursi del mundo” (113). Transgresora, audaz, se sitúa a menudo en el límite, enmarcando su actitud en la corriente modernizadora que ha traído la industrialización. Del mismo modo se aprecia en su anticlericalismo. En la autobiografía, los párrafos son numerosos y la Iglesia Católica — “uno de los principales enemigos del progreso, no sólo en México sino en toda Latinoamérica” (245) — recibe ataques muy fuertes. En esta opción, María Félix también se está jugando un espacio en los vínculos de la actitud laicizante generalizada por el proceso revolucionario. Es decir, esta postura del sujeto de la narración autobiográfica se afinca en profundas corrientes de pensamiento y acción — basta recordar la guerra contra los “cristeros”- de la revolución mexicana. Lo que no quiere decir que estamos ante una propuesta de sobriedad espiritual frente al desborde de la Iglesia. No. El personaje María Félix se construye en un espacio de privilegio, que considera propio y meritorio, y que —a pesar de su transgresión — responde a los rituales de los 
sectores privilegiados en donde se difumina lo que ella considera la aristocracia del espíritu con el poder económico o el poder político. En este último, su funcionamiento se observa en términos de relaciones cortesanas de amistad y favores recíprocos.

¿Quienes son los destinatarios de este discurso hacia donde se direcciona el sujeto María Félix? El sujeto de la enunciación habla desde una posición de celebridad que, desde ya, justifica su discurso y el carácter de éste, dirigido, por una parte, al público nacional para quien declara su orgullo de ser mexicana, su responsabilidad frente a ello. Pero, también, a un público internacional: "represento a mi país en el extranjero", escribe (28). "No soy únicamente yo —insiste- soy la imagen de mi nación” (28). El lazo con este público tiene que ver con la mirada exotizante de Europa sobre América, del extranjero sobre México, pero, también en su caso, el efecto de la seducción que produce lazos eficaces a través del espacio y el tiempo. Porque hay otros destinatarios: sus contemporáneos, ante quienes se presenta como dialogante o se muestra entrando en la polémica entre Carlos Fuentes y Octavio Paz (179-180); o bien opina sobre la historia mexicana que le es actual. Por lo demás, el personaje de la narración autobiográfica se está construyendo para el futuro, enumerando los homenajes que se le hacen -_"En Buenos Aires me recibieron como en Madrid: con una manifestación de júbilo popular” (131) situándose en la historia desde una posición de celebridad adquirida que lo justifica todo. En suma, entrar en la autobiografía de María Félix significa desentrañar una maraña de vínculos con su espacio nacional, con el internacional, con el presente y el futuro de acuerdo al sujeto autobiográfico que ella construye. El resultado es la comprensión, la apertura a los elementos que observamos en una construcción identitaria. No dejamos por ello de continuar seducidos por la imagen del personaje, por el guiño de la ceja y por el movimiento del pelo que marcan una época de la cultura de México y de América Latina y que logran desplazarse más allá y situarse en el eje de la sensibilidad de ese panteón laico que identifica a nuestra cultura popular de masas. No dejamos de verla con la fusta en la mano y con las botas caminando con firmeza por el llano venezolano o, tal vez, envuelta en un impermeable por un costado del Zócalo, alta y delgada; el ala del sombrero levemente inclinada, mientras en el fondo, en un gran letrero, se lee: "Mejor mejora Mejoral”.

Universidad de Santiago de Chile* Instituto de Estudios Avanzados (IDEA) Román Díaz 89, Providencia, Santiago (Chile) ana.pizarro@usach.cl 


\section{BIBLIOGRAFÍA}

AUGÉ, Marc. Los "no lugares”. Espacios del anonimato. Barcelona: Gedisa, 1998.

AVEDOY GUERRERO, Fernando (2006). "Los primeros años de trabajo”, en http://www.wradio.com.mx/historia.asp?id=196949. Última consulta: 14 de marzo de 2008.

CANO, Gabriela. "Ciudadanía y sufragio femenino: el discurso igualitario de Lázaro Cárdenas”, en Lamas, Marta (coord.). Miradas feministas sobre las mexicanas del siglo XX. México: F.C.E., 2007.

DE MAN, Paul. “A utobiography as De-Facement”, en Modern Language Notes, N 94, 1979.

FÉLIX, María. Todas mis guerras. México: Clío, 2005.

FRANCO, Jean. Las conspiradoras. La representación de la mujer en México (versión actualizada). México: F. C. E., 1993.

GONZÁLEZ RODRÍGUEZ, Sergio. "La ciudad de México y la cultura urbana”, en Blanco, José Joaquín y José Woldenberg (comp.). México a fines de siglo. Tomo I. México: F. C. E., 1993.

KLEIN, Eva. "Sobre las dificultades de definir la autobiografía como género", en Márgara Russotto. La ansiedad autorial. Caracas: Equinoccio, 2006.

KRAUZE, Enrique. "Corazón de hombre”, en Félix, María, Todas mis guerras. México: Clío, 2005.

LEVINAS, Emmanuel. Outside the subject. Londres: The Athlone Press,1993.

LISPECTOR, Clarice. Agua viva. Río de Janeiro: Artenova, 1973.

LOUREIRO, Ángel. “Autobiografía, el rehén singular y la orgía invisible”, en Russotto, Márgara (comp.). La ansiedad autorial. Caracas: Equinoccio, 2006.

MONSIVAIS, Carlos. Aires de familia. Cultura y sociedad en América Latina. Barcelona: Anagrama, 2000.

PAZ, Octavio. "Razón y elogio de María Félix”, en Miscelánea II. Obras Completas, Vol. 14. México: F. C. E., 2001.

RUSSOTTO, Márgara. “¿Cuál autoría? Sociedad y escritura en el diario íntimo femenino”, en Russotto, Márgara (comp.). La ansiedad autorial. Caracas: Equinoccio, 2006.

SAMPER, Juanita. María Félix. María Bonita, María del Alma. Bogotá: Panamericana, 2005.

TAIBO I, Paco Ignacio. María Félix. 47 pasos por el cine. México: B, 2002. 